\title{
La Comisión Europea como intermediario en las redes de políticas públicas
}

\author{
Susana Borrás
}

Resumen: Las recientes transformaciones en el seno de la Unión Europea han estado ejerciendo una presión significativa en la función gestora de la Comisión Europea. Examinando su función de intermediación, este artículo se pregunta que clase de papel juega la Comisión en las interacciones políticas en Bruselas después del año 2000. Desarrollando un marco conceptual acerca de los papeles de intermediación en la política de la Unión, este artículo emplea una combinación de datos cualitativos y cuantitativos en un análisis empírico de dos casos extremos en los que la Comisión ha estado enredada en los últimos años. El artículo sostiene que los informes previos al "fallecimiento" de la Comisión fueron muy exagerados, porque ésta continua jugando un papel de liderazgo en la gestión de interacciones entre múltiples actores a distintos niveles de gobernación. Los resultados empíricos muestran que la Comisión es un resistente intermediario central en las redes sociales.

Palabras clave: Comisión Europea, policy network, procedimiento de codecisión, método abierto de coordinación, Estrategia Europea de Empleo, organismos genéticamente modificados, intermediación de intereses.

\section{INTRODUCCIÓN}

Descrita como el "motor de la integración europea", no es aventurado afirmar que la etapa posterior a la era Delors ha demostrado ser turbulenta para la Comisión Europea en lo que, generalmente, se ha percibido como una pérdida de su previo papel de liderazgo. Una serie de escándalos vinculados a la seguridad alimentaria y con la mala gestión dio lugar a la primera dimisión jamás registrada en el Colegio de Comisarios en 1999, llevando a la Comisión a sus niveles históricos más bajos de confianza política y administrativa (Judge y Earnshaw, 2002) y obligándola a adoptar amplias reformas internas iniciadas inmediatamente después por Prodi (Metcalfe, 2000). Además, la expansión del papel del Parlamento Europeo y la propagación del procedimiento de codecisión (Burns, 2004), parecen haber afectado a la posición relativa 
de la Comisión en el proceso de toma de decisiones frente a otras instituciones de la UE. Del mismo modo, los "nuevos modos de gobernanza", que intentan lograr la coordinación voluntaria de los Estados miembros y los actores privados en ausencia de una regulación supranacional, parecen socavar la posición de la Comisión en el seno de la Unión (Wincott, 2001).

El punto de partida de este artículo es que la prominente importancia de estos cambios y sus posibles repercusiones en la gestión y en la función burocrática de la Comisión, están reabriendo el tradicional debate académico sobre el papel de la Comisión. Esta labor debería hacerse partiendo de estudios y análisis empíricos para lo que, previamente, es necesario reexaminar los marcos analíticos existentes con sumo cuidado para mejorar su precisión conceptual y su capacidad analítica de exposición.

La principal cuestión que se aborda en este artículo es la naturaleza de la función desempeñada por la Comisión en las interacciones en Bruselas después del año 2000. Proporcionar respuestas fiables requiere un paso más en la clarificación conceptual del papel de intermediación. Con este propósito, se utiliza el análisis de redes sociales (social network analysis) para desarrollar una tipología específica de los papeles de intermediación; una tipología que constituye un marco analítico más amplio y más matizado para el estudio de las diferentes funciones de la Comisión y de su importancia específica en las redes de políticas públicas (policy network) en el ámbito de la UE.

Empleando una combinación de datos cuantitativos y cualitativos (datos relacionales cuantificados y entrevistas individuales, respectivamente), el artículo examina dos casos que han generado una gran tensión en la Comisión en los últimos años, en la medida en que han puesto en cuestión su rol convencional. Explorar la naturaleza de las funciones asumidas por la Comisión en el marco de estas dos destacadas circunstancias, puede proporcionar pruebas de la función de la Comisión en situaciones más triviales. Estos casos son el nuevo régimen regulador de los organismos genéticamente modificados (OGM) -denominados habitualmente organismos transgénicos-, aprobado en 2004, y la definición de las directrices comunes de la Estrategia Europea de Empleo (EEE) en 2003. El primero es muy interesante la ser el resultado directo de la pérdida de confianza del público y de los Estados miembros en la gestión de la Comisión de estas nuevas sustancias tras las secuelas de los escándalos alimentarios de finales de la década de los 90. Además, las demandas para establecer un nuevo régimen regulador de los OGM fueron explícitamente dirigidas para rediseñar el papel formal de la Comisión. El segundo caso es también muy interesante por dos razones; por un lado, la EEE está sujeta al “método abierto de coordinación”, una de las nuevas formas de gobernanza que sigue un muy novedoso procedimiento que no requiere una acción legislativa; y, por otro lado, la creación del EMCO (Employment Committee/Comité de Empleo), un poderoso comité formado por representantes nacionales para poner en marcha este método abierto de coordinación, ha relegado prima facie el papel de la Comisión en términos formales e informales. Ambas razones 
analizar en detalle el cambiante papel de la Comisión en los momentos decisivos a partir del año 2000.

\section{LÍMITES PREVIOS PARA EL ANÁLISIS}

A pesar de la masiva atención académica, el papel específico de la Comisión en el proceso de elaboración de las políticas públicas de la UE ha seguido siendo un tema muy controvertido desde los años 60 y aún hoy requiere una mayor investigación empírica (Nugent, 2000; Matlary, 2000; Dimitrakopoulos, 2004). El punto de partida convencional del enfoque intergubernamentalista es, en general, deductivo, centrándose concretamente en las condiciones específicas de las relaciones de los principales agentes responsables de la delegación de poderes. A partir de ahí, se identifican una serie de condiciones que limitan la autonomía de la Comisión en sus vis-a-vis con los Estados miembros. El principal argumento es que la Comisión está estructuralmente limitada por las opciones institucionales de los Estados miembros (Moravcsik, 1999; Garrett, 1992). En los últimos años, la Comisión ha estado limitada además por los sucesivos cambios en las relaciones interinstitucionales en la UE que han fortalecido sistemáticamente a los Estados (Majone, 2002). Un fortalecimiento que no es sólo estructural, sino que también es un resultado directo de su voluntad de confinar el vigor político de la Comisión en el período posterior a la era Delors (Kassim y Menon, 2004). Aunque interesante, la prominencia del foco en cuestiones de delegación deja la aproximación intergubernamental mal preparada para estudiar las interacciones entre las instituciones de la UE y otros agentes no gubernamentales en las interacciones políticas, formales e informales, que tienen lugar en Bruselas con carácter previo a la toma de decisiones políticas. En otras palabras, los resultados de la investigación sobre la Comisión como un actor limitado, arrojan poca luz sobre la cuestión de qué tipo de papeles de intermediación desempeña la Comisión dentro de sus estrechos límites de actuación.

Los analistas de instituciones supranacionales proporcionan un punto de vista algo diferente, retratando a la Comisión en términos más autónomos. Destacan que, a pesar de la centralidad de los Estados miembros en la política de la UE, existen importantes lagunas en el control de los Estados miembros sobre el proceso de integración europea, principalmente con respecto a la formulación de políticas en el día a día (Pierson, 1998; Marcas et al., 1997). Una de estas lagunas se produce precisamente en relación con la propia autonomía de las instituciones europeas, que tienden a seguir sus propias preferencias y a forjar alianzas con diferentes tipos de actores en la arena de la UE (Schmidt, 2004). Esta perspectiva abrió la puerta a una serie de análisis sobre la política emprendedora de la Comisión y sobre la interacción de la Comisión con los diversos actores protagonistas de la formulación de políticas en la UE, demostrando que la Comisión desempeñó un papel fundamental en la creación de redes de políticas públicas en la década de los 90. A la vista de las recientes transformaciones contextuales, este artículo pretende aclarar hasta qué extremo son válidas estas conclusiones. 
Cram percibe a la Comisión como un "oportunista decidido" que domina la capacidad "para responder a las oportunidades en cuanto se presentan e incluso para facilitar la aparición de estas oportunidades” (Cram, 1997: 156). En una línea similar, Pollack sostiene que la Comisión está particularmente bien situada para ser un exitoso emprendedor de políticas dentro de la política de la UE. En primer lugar, porque tiene un conjunto de características clave que son muy importantes en términos relacionales, concretamente experiencia, habilidades de intermediación y persistencia institucional. En segundo lugar, porque disfruta del monopolio de iniciativa en los procedimientos legislativos formales, lo que supone una ventaja adicional con respecto a otras instituciones de la UE. Y en tercer lugar, porque goza de una posición central en las bien desarrolladas y densas redes de políticas públicas en Bruselas (Pollack, 1997: 126).

Siguiendo estos argumentos, otros autores describen la Comisión como una organización activa con un conjunto de técnicas distintas, cuya influencia relativa depende en gran medida de sus relaciones con su contexto político, en particular con los intereses no estatales involucrados en el ámbito de la política específica en juego (Chistiansen, 2001).

Estos estudios han arrojado mucha luz sobre la integración de la Comisión en las interacciones políticas formales e informales. Sin embargo, no se han ocupado en absoluto del papel de intermediación de la Comisión, y si lo han hecho ha sido indirectamente. Es decir, el punto principal de los análisis anteriores ha sido enfatizar que la Comisión opera en las redes de políticas públicas y que éstas son importantes para explicar su posición política en relación a la formulación de políticas de la UE. Pero las cuestiones relativas a las funciones específicas que la Comisión desempeña y en qué medida estos roles han ido cambiando desde el año 2000 son temas que siguen estando inexplorados en gran medida. Cubrir estos puntos ciegos implica invertir la corriente de estudio y comenzar por buscar de herramientas analíticas específicas que ofrezcan criterios eficaces para evaluar el papel de la Comisión desde el año 2000'.

La integración de la Comisión en una compleja red de relaciones a nivel supranacional está vinculada, en los estudios sobre la UE, a un conjunto de nociones analíticas con un enfoque basado en los actores, en concreto, en las policy networks o redes de políticas públicas. El estudio de las interacciones políticas informales en el proceso político y en el sistema general de gobernanza de la UE ha ido ganando cada vez ma-

1 Los motivos para elegir este lapso de tiempo se citan en la introducción de este artículo, en concreto, los turbulentos tiempos para la Comisión después de 1999 en relación con la dimisión de la Comisión Santer, la crisis de legitimidad debida a los escándalos sobre seguridad alimentaria asociados a la mala gestión de la Comisión y el surgimiento de modos alternativos de gobernanza tras la estrategia de Lisboa puesta en marcha en el año 2000 (en particular, el método abierto de coordinación), todos los cuales parece que socavaron la posición central de la Comisión a partir del año 2000. Por otra parte, la ampliación a 25 miembros en 2004 y posteriormente a 27 en el año 2007, es otra poderosa razón para investigar el papel 
yor atención académica en el ámbito de los estudios sobre la UE. Peterson (2004) sostiene que la razón que subyace detrás de esta atención académica acumulada es que la naturaleza del sistema político de la UE se presta a ello; uno, porque se caracteriza por una elevada división en las áreas de políticas sectoriales; dos, porque los expertos y las organizaciones no gubernamentales tienen una gran relevancia en el proceso informal de elaboración de políticas; y tres, porque hay "un extraordinario y complejo laberinto de comités que dan forma a las opciones de las políticas" (Peterson, 2004: 118). No existen teorías completas sobre las policy networks ni en la tradición anglosajona ni en la germánica, pero, sin embargo, la metáfora de las redes ha sido útil analíticamente para intentar establecer la causalidad existente entre las características de las redes de políticas públicas y los resultados de las políticas sectoriales particulares (Börzel, 1998). En otras palabras, los analistas se han mostrado particularmente interesados en determinar en que medida la estructura precisa de una red de políticas públicas ayuda a explicar los resultados de las políticas en particular, por ejemplo, en el ámbito de la política tecnológica, la política agrícola o la política de cohesión (Peterson, 1991; Daugbjerg, 1999; Ansell et al., 1997).

El estudio de la estructura de las redes de políticas públicas y su impacto en las políticas ha estado muy inspirada por las primeras obras de Rodhes sobre política británica (Rodhes, 1990), centrado principalmente en la cuestión del grado de integración en la red y la dinámica de exclusión-inclusión dentro de ella. El continuo de Rodhes entre dos extremos ideales de unas "comunidades de políticas públicas" altamente integradas y muy exclusivas, por un lado, y unas "redes de problemas" débilmente integradas e inclusivas, por otro, ha demostrado ser una herramienta útil para caracterizar la estructura de una red en particular y, por ende, para su utilización como una variable independiente que explique los resultados de las políticas. La hipótesis comprobable subyacente en los análisis de las redes de políticas públicas en los estudios sobre la UE ha sido que cuanto más integrada y exclusiva sea la "comunidad de políticas", menos radical será el cambio en la política concreta. "Dicho de otro modo, los resultados de las políticas de la UE vienen determinados en función de cuan integradas y exclusivas sean las redes de políticas específicas y en función cuanto sean mutuamente dependientes los actores que intervienen en la red. Debemos esperar diferentes tipos de resultados en sectores firmemente integrados y donde cabalísticas comunidades de políticas son los guardianes del orden del día, como es el sector farmacéutico o el agrícola, que en aquellos sectores poblados por redes de problemas dictatorialmente limitadas, tales como la política de medio ambiente "(Peterson, 2004b: 124). Sin embargo, por muy interesante que pueda ser centrarse en la densidad, el análisis de las redes de políticas públicas en los estudios de la UE, debe dar un paso más allá del mero estudio de las redes como tales y profundizar en la posición relativa de determinados actores dentro de las mismas. Esta perspectiva sobre los actores individuales es especialmente necesaria en vista de la investigación actual sobre la Comisión, y es particularmente interesante si se consideran los diferentes papeles de la Comisión en las distintas áreas de las políticas de la UE y su cambiante centralidad en el contexto de las nuevas tendencias de gobernanza frente a las otras instituciones de la UE y los Estados miembros (Calonge Velásquez, 2004). 
Los límites analíticos de los enfoques anteriores, por lo tanto, reclaman más esfuerzos para avanzar hacia un marco analítico más preciso capaz de ofrecer resultados exactos sobre la naturaleza de los papeles de intermediación realizadas por la Comisión desde el año 2000. Con este propósito, el siguiente apartado desarrolla un marco basado en una tipología de las funciones de intermediación, contextualizando estas funciones en el proceso de toma de decisiones en la UE y en la identificación de tres características organizativas internas de la Comisión que ayudan a explicar cómo esta institución ha desarrollado los papeles de intermediación en esta cuestión.

\section{LAS FUNCIONES DE INTERMEDIACIÓN DE LA COMISIÓN: EL MARCO CONCEPTUAL}

Generalmente se entiende por intermediación (brokerage) la posición intermedia que adopta un actor entre otros dos agentes, que son denominados respectivamente el "remitente" y "el receptor". El estudio de las posiciones de intermediación de los diferentes actores en las redes proporciona información a dos niveles. En primer lugar, es capaz de captar el rol o roles específicos que los diferentes actores han asumido y su posición central relativa en la red; y, en segundo lugar, ofrece nuevas percepciones interesantes en relación a los tipos de flujos más destacados que tienen lugar en la red en su conjunto. Estudiar la posición de la Comisión en el seno de estas interacciones en las redes permite conocer el papel de la institución en el proceso político desde el punto de vista de la gestión de las políticas (Laffan, 1997; Talleberg, 2002; Pollitt y Bouckaert, 2004), y que contrasta con los enfoques que contemplan a la Comisión como una organización de red en sí misma (Metcalfe, 1996).

En 1989, Gould y Fernández propusieron una interesante tipología conceptual con cinco tipos distintos de roles de intermediación (Gould y Fernández, 1989). Trabajando principalmente con métodos cuantitativos de análisis de redes sociales, estos autores dividieron a los actores de las redes en diferentes grupos de acuerdo con sus rasgos comunes. Los papeles de intermediación se definen sobre la base de la interacción entre los actores dentro y fuera de estos grupos de acuerdo con la identidad del remitente y el receptor. En concreto, Gould y Fernández proponen los siguientes cinco roles de intermediación: el coordinador, el guardián, el representante, el consultor y el enlace. El de coordinador es el papel que se juega cuando el remitente, el receptor y el intermediario son del mismo grupo; el de guardián, cuando el remitente es de un grupo diferente y el receptor y el intermediario son del mismo grupo; el de representante, cuando el remitente y el intermediario son del mismo grupo pero el receptor es de un grupo diferente; el de consultor cuando el remitente y el receptor son del mismo grupo, pero el intermediario es de otro grupo; $y$, finalmente, el de en-

24 tenecen a tres grupos diferentes. 


\section{CUADRO 1}

Papeles de intermediación de acuerdo con el grupo de origen del remitente, del receptor y del intermediario

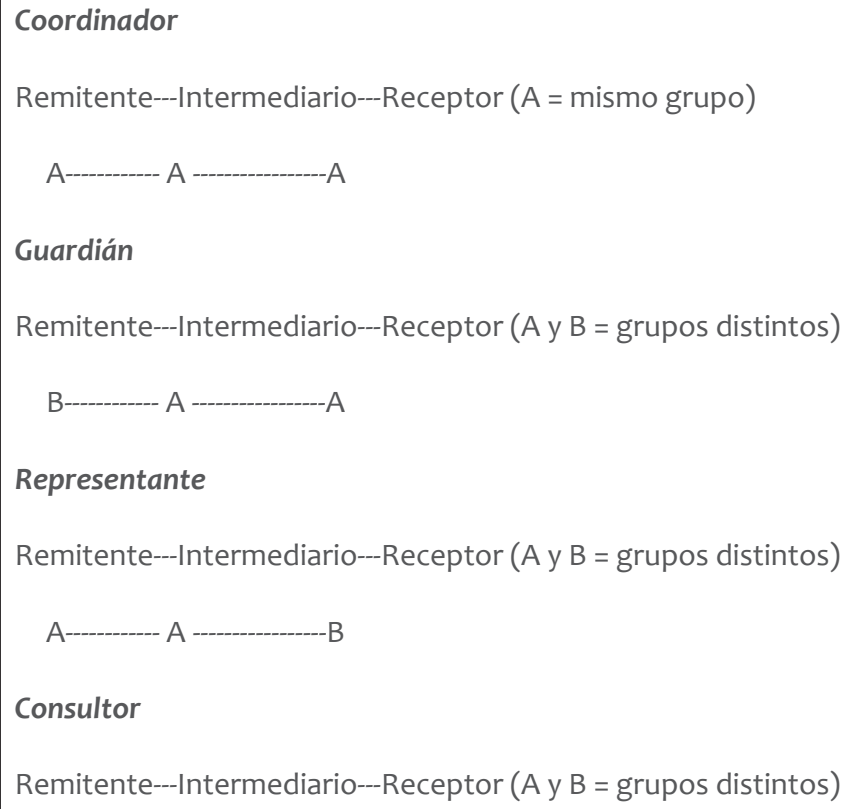

\section{Guardián}

Remitente---Intermediario---Receptor (

\section{Representante}

Remitente---Intermediario---Receptor ( $\mathrm{A}$ y $\mathrm{B}$ = grupos distintos)

\section{Consultor}

Remitente---Intermediario---Receptor ( $\mathrm{A}$ y $\mathrm{B}$ = grupos distintos)

\section{Enlace}

Remitente---Intermediario---Receptor (A, B y C = grupos distintos)

$A-C$

Fuente: Gould y Fernández (1989).

Estas cinco definiciones se han elaborado deductivamente y recogen todas las combinaciones posibles sobre el origen del grupo del remitente, del intermediario y del receptor de las interacciones. Es importante resaltar que las interacciones se producen en un único de único sentido, donde el remitente nos ha indicado que se ha puesto en contacto con otra organización, y el receptor es la organización a la que tales contactos se han dirigido.

Con el fin de que sea plenamente operativa en el ámbito de los estudios sobre la UE, es preciso realizar una aclaración conceptual adicional en relación con los grupos dentro de las redes de políticas públicas europeas. Las redes de políticas públicas en la UE están formadas por complejas interacciones entre muy diversos tipos de acto- 
res grupales que a su vez pueden dividirse en diferentes subgrupos. El Grupo más importante es el formado por las instituciones más relevantes la UE: la Comisión, el Parlamento Europeo, el Consejo de Ministros y el Tribunal Europeo de Justicia. Un segundo grupo está formado por organismos menos relevantes de la UE, tales como el Comité Económico y Social, el Tribunal de Cuentas, el Comité de las Regiones, el Defensor del Pueblo, etc., que comparten en común con las anteriores el hecho de tener atribuidas tareas específicas y constitucionalmente definidas en el proceso de formulación de políticas de la UE. Junto a estos dos grupos, existen toda una serie de grupos de diferente tamaño formados por stakeholders del sector privado en el área de la política correspondiente (interlocutores sociales, asociaciones industriales y de empresas, grupos con intereses medioambientales, asociaciones de consumidores, oficinas de representación infranacionales, etc.).

Las prerrogativas formales de las instituciones de la UE en el proceso de formulación de políticas significa que este grupo particular posee una especial importancia en el conjunto de la red, principalmente porque es en este contexto donde las decisiones finales son adoptadas. Naturalmente, las interacciones políticas dentro de la red tenderán a estar dirigidas a ejercer el máximo posible de influencia política sobre este grupo en particular. Del mismo modo, la posición específica y los papeles de intermediación asumidos por cada una de las instituciones de la UE en este grupo no sólo sacarán a la luz los diferentes puestos clave dentro de la red, sino que también tendrá efectos importantes sobre los resultados de las políticas. Dado que el presente estudio está interesado en la cuestión del cambiante papel de la Comisión, es necesaria una aclaración conceptual más con respecto a las diferentes fortalezas de los papeles de intermediación en las redes de políticas públicas de la UE.

Como ponen de relieve las anteriores definiciones de los papeles de intermediación, el coordinador es un actor que desempeña su papel dentro de un grupo específico. En términos generales, la oportunidad de la Comisión para desplegar tal función de coordinación dentro de su grupo específico (el formado por las instituciones más importantes de la UE) depende en gran parte de qué tipo de prerrogativas formales tenga este organismo en el proceso de toma de decisiones y en especial en los procedimientos legislativos (si bien no hay que olvidar las interacciones informales). El papel del "coordinador" es importante por dos razones; en primer lugar, porque el "coordinador" goza de una superior presencia política y visibilidad, ya que la mayor parte de las otras instituciones lo han elegido como un intermediario valioso; y; en segundo lugar, porque el "coordinador" está en una posición más favorable para gestionar el contenido y la orientación de los flujos de información dentro del grupo. El papel de "guardián" es también un muy importante papel de intermediario. El guardián está en una posición clave para controlar el flujo de información procedente de agentes de otros grupos hacia su propio grupo, lo que adquiere especial relevancia en el caso de la Comisión Europea, habida cuenta del papel central de intermediación entre la variedad de grupos formados por interesados privados y el grupo forma26 do por las principales instituciones europeas. 
En contraste con la gran importancia del “coordinador” y del “guardián”, el papel de intermediación del "representante", del "consultor" y del "enlace" son notablemente más débiles en particular en el contexto de las redes de políticas públicas de la UE y, en particular, desde la perspectiva de la Comisión. En estos tres roles la Comisión actúa como intermediario en relación con flujos que son políticamente menos relevantes, ya que el destinatario no es el grupo central de instituciones de la UE donde se adoptan finalmente las decisiones, sino otros grupos. En consecuencia, estas interacciones tienen una capacidad limitada para ejercer influencia sobre las decisiones, y el intermediario (la Comisión, en este caso) cumple más una función de comunicación de las instituciones de la UE con el resto de actores de la red de políticas públicas.

En la anterior conceptualización de los cinco papeles de intermediación en el proceso de toma de decisiones en la UE, hay un entendimiento explícito de que no todos estos papeles son igualmente relevantes o fuertes en términos políticos. Si los colocamos en una dicotomía imaginaria, "coordinador" y "guardián" son las formas más fuertes de intermediación en la red de políticas públicas, ya que sus respectivas posiciones les permiten ejercer una notable influencia política (Figura 1).

FIGURA 1

Papeles de intermediación fuertes y débiles en la formulación de políticas públicas de la UE

\begin{tabular}{|l|l|}
\hline & Representante \\
Guardián & Consultor \\
\hline Intermediación fuerte & Enlace \\
\hline
\end{tabular}

Fuente: Elaboración propia a partir de Gould y Fernández (1989).

La posición relativa de la Comisión en las redes, con papeles de intermediación más fuertes o más débiles y con mayor o menor centralidad, depende en gran medida de tres características organizativas internas. En primer lugar, de su capacidad para desarrollar un liderazgo político moral, que se define aquí como la capacidad de persuadir a los diversos actores en la obtención de resultados que demandan consenso, o al menos resultados de compromiso. Esto es de suma importancia en la compleja configuración política de la UE, en la que el grado de diversidad entre Estados y entre actores es muy grande. En segundo lugar, la aptitud de la Comisión para explotar su capacidad institucional en cuanto a los conocimientos de su personal. Este factor es particularmente importante en contextos con un alto contenido científico y técnico, donde la movilización efectiva de los recursos interiores de conocimiento es esencial para el cumplimiento de papeles de intermediación fuertes. Por último, pero no por ello menos importante, los papeles de intermediación de la Comisión y su preponderancia también dependerán del despliegue exitoso de su competencia como gestor, en concreto, la forma en que la organización sea capaz de procesar múltiples fuentes 
de información y canalizar de forma selectiva esta información en relación con propósitos estratégicos determinados.

Las cambiantes condiciones reseñadas en la introducción de este artículo han situado a la Comisión bajo presión. Es por ello razonable preveer, al menos, dos rasgos en su actuación como intermediario en las redes de políticas públicas de la UE, que pueden ser formuladas como dos hipótesis. La primera sería que otros organismos (ya sean actores o instituciones) han cuestionado la posición de la Comisión como el intermediario más importante. Y la segunda se relaciona con el tipo de papeles de intermediación desempeñados por la Comisión. Se podría esperar que la Comisión tenga tendencia a desempeñar papeles de intermediación que son débiles, es decir, papeles de intermediación que son principalmente de "representante", "consultor" y/o "enlace”.

Con el fin de comprobar estas dos hipótesis, los siguientes apartados desarrollan un análisis basado en datos cuantitativos y cualitativos los casos anteriormente señalados: la regulación de los OGM y la Estrategia Europea del Empleo. El método cuantitativo sigue el llamado "análisis de redes sociales", que utiliza mediciones estadísticas en el estudio de datos relacionales (Cuadro 2). El análisis de redes sociales tiene una larga tradición en las ciencias sociales, en particular en el campo de la Sociología, y su uso en la Ciencia Política y de la Administración es cada vez mayor. En consonancia con esta tradición, el presente estudio realiza una serie de mediciones seleccionadas de posiciones centrales y de papeles de intermediación en ambas redes. Los datos cualitativos, recopilados en forma de una serie de entrevistas individuales con los principales interesados e instituciones de la UE, se han utilizado para triangular y complementar los resultados cuantitativos².

\section{CUADRO 2}

Fuentes de los datos de los dos casos en estudio

\begin{tabular}{|c|c|c|}
\hline & $\begin{array}{c}\text { Cuestionarios de red válidos } \\
\text { (datos cuantitativos) }\end{array}$ & $\begin{array}{l}\text { Entrevistas individuales } \\
\text { (datos cualitativos) }\end{array}$ \\
\hline $\begin{array}{l}\text { Caso } \\
\text { OMG }\end{array}$ & $\begin{array}{l}34 \text { cuestionarios de red válidos } \\
\text { - } 6 \text { Miembros del Parlamento Europeo } \\
\text { - } 2 \text { Representantes nacionales } \\
\text { - } 3 \text { Funcionarios de la Comisión } \\
\text { - } 4 \text { Asociaciones de consumidores } \\
\text { - } 8 \text { Asociaciones industriales } \\
\text { - } 4 \text { Asociaciones medioambientales } \\
\text { - } 4 \text { Asociaciones agrícolas } \\
\text { - } 2 \text { Expertos científicos } \\
\text { - } 1 \text { ONG de ayuda al desarrollo }\end{array}$ & $\begin{array}{l}\text { 17 entrevistas } \\
\text { - } 5 \text { Miembros del Parlamento Europeo } \\
\text { - } 1 \text { Representante nacional } \\
\text { - } 2 \text { Funcionarios de la Comisión } \\
\text { - } 2 \text { Asociaciones de consumidores } \\
\text { - } 3 \text { Asociaciones industriales } \\
\text { - } 1 \text { Asociación medioambiental } \\
\text { - } 2 \text { Asociaciones agrícolas } \\
\text { - } 1 \text { Experto científico }\end{array}$ \\
\hline
\end{tabular}

28 de datos cuantitativos y cualitativos para el análisis de redes en los estudios sobre la UE. 
CUADRO 2 (cont.)

Fuentes de los datos de los dos casos en estudio

\begin{tabular}{|c|c|c|}
\hline & $\begin{array}{l}\text { Cuestionarios de red válidos } \\
\text { (datos cuantitativos) }\end{array}$ & $\begin{array}{l}\text { Entrevistas individuales } \\
\text { (datos cualitativos) }\end{array}$ \\
\hline $\begin{array}{l}\text { Caso } \\
\text { EEE }\end{array}$ & $\begin{array}{l}17 \text { cuestionarios de red válidos } \\
\text { - } 2 \text { Miembros del Parlamento Europeo } \\
\text { - } 4 \text { Comité de Empleo } \\
\text { - } 3 \text { Comisión } \\
\text { - } 2 \text { ETUC } \\
\text { - } 1 \text { UNICE } \\
\text { - } 1 \text { CEEP } \\
\text { - } 1 \text { DA } \\
\text { - } 1 \text { Comité de las Regiones } \\
\text { - } 1 \text { Comité Económico y Social } \\
\text { - } 1 \text { EAPN }\end{array}$ & $\begin{array}{l}13 \text { entrevistas } \\
\text { - } 2 \text { Miembros del Parlamento Europeo } \\
\text { - } 3 \text { Comité de Empleo } \\
\text { - } 1 \text { Comisión } \\
\text { - } 2 \text { ETUC } \\
\text { - } 1 \text { UNICE } \\
\text { - } 1 \text { CEEP } \\
\text { - } 1 \text { DA } \\
\text { - } 1 \text { Comité de las Regiones } \\
\text { - } 1 \text { EAPN }\end{array}$ \\
\hline
\end{tabular}

Fuente: Elaboración propia. Los datos para el caso OGM se recopilaron entre septiembre y diciembre de 2004, mientras que los relativos al caso EEE se recogieron entre enero y junio de 2005 .

En los cuestionarios de red, los encuestados proporcionaron información relativa a las organizaciones con las que interactúan regularmente. No se les pidió que evaluaran los diferentes papeles de intermediación de la Comisión, sino sólo que proporcionaran información sobre las otras organizaciones con las que mantenían contactos regulares. A los datos relacionales se les asignó un valor binario (valores 0-1) y se agruparon en dos matrices para los casos OGM y EEE, de 18x18 y $10 \times 10$ organizaciones, respectivamente. Los cuestionarios fueron recogidos bien a continuación de la entrevista individual o bien fueron remitidos por correo. Las entrevistas individuales constaban de preguntas abiertas y amplias que produjeron más información cualificada acerca de las interacciones.

Las mediciones del análisis de redes sociales se realizaron utilizando el programa UCINET-6. El tamaño de la "egored" y la centralidad "betweenness" se midieron utilizando la matriz binaria como única fuente. Las mediciones de la intermediación se realizaron utilizando la matriz como fuente y como vector de partición, un archivo de atributos con la división de las organizaciones en los diferentes grupos.

\section{LA COMISIÓN EN LA RED DE POLÍTICAS PÚBLICAS OGM}

La configuración de un nuevo marco regulador para el lanzamiento al mercado -y al medio ambiente- de los organismos transgénicos (OGM) fue un tema polémico en la política de la UE (Pollack y Shaffer, 2005). Estos organismos, que son modificados a través de sofisticados métodos (que en ocasiones implican la transferencia de genes de otras especies naturales), fueron objeto del escrutinio público debido a las incertidumbres científicas en torno a su seguridad para el medio ambiente y para los consumidores. 
El debate europeo sobre los OGM tuvo lugar inmediatamente después del estallido de las crisis sobre la EEB (enfermedad de las vacas locas) y sobre las dioxinas y la seguridad alimentaria. La principal fuente del descontento por los OGM en Europa fue la estructura del procedimiento de aprobación a nivel de la UE, que no se consideraba que fuera transparente ni que estuviese basado en pruebas científicas suficientes. Como resultado de estas tensiones, la UE impuso una moratoria de facto en 1998 a la aprobación de los OGM hasta que se estableciera un nuevo marco regulador. El proceso posterior de toma de decisiones sobre estas nuevas normas se llevó a cabo en medio de un clima político muy tenso entre las partes interesadas (asociaciones industriales, de consumidores, de medio ambiente, agrícolas y ONG's de ayuda al desarrollo), con posiciones nacionales muy alñejadas y con un Parlamento Europeo muy dividido. Además de crear procedimientos de aprobación más transparentes, la normativa final se apoyó mas en los intereses de los consumidores que en la protección del medio ambiente, ya que en los nuevos requisitos de etiquetado se siguió la filosofía de “la elección del consumidor” (Skogstad, 2003).

El aspecto más interesante de este caso es que la Comisión era al mismo tiempo parte del problema (porque estaba bajo presión) y parte de la solución (porque tenía que iniciar el proceso legislativo que siguió al procedimiento de codecisión). Formalmente la Comisión conservó el monopolio de la iniciativa. No obstante, la resolución del "enigma" de los OGM exigió mucho más que el ejercicio de poderes formales. Requirió un mínimo grado de liderazgo moral a fin de alcanzar un compromiso entre los muy variados y complejos intereses, un alto grado de capacidad institucional, dadas características técnicas y el conocimiento intensivo de esta política, y una amplia dosis de capacidad gerencial dado el tamaño de la de red de políticas públicas.

Midiendo las puntuaciones de los papeles de intermediación desempeñados por los 18 actores en la matriz, la Tabla 1 pone de manifiesto varios aspectos interesantes. La Comisión consigue las puntuaciones más altas en la mayoría de las funciones de intermediación, lo que significa que es el intermediario más destacado en la red OGM, como se indica por el número total de las puntuaciones. Así, a pesar de las turbulencias en torno a la toma de decisiones relativas a la regulación de los OGM, la Comisión consiguió evitar ser sustituida por otras instituciones u organizaciones. Dicho esto, merece la pena destacar que la Comisión desempeñó principalmente el papel de guardián y representante de los flujos entre su propio grupo de instituciones de la UE y los otros actores interesados, pero no jugó ningún papel de coordinación dentro del grupo de instituciones de la UE.

\section{TABLA 1}

Puntuaciones de intermediación en la red OGM

\begin{tabular}{|l|l|c|c|c|c|c|c|}
\hline Tipo de organización & Organizaciones & Coordinación & Guardián & Representante & Consultor & Enlace & Total \\
\hline Instituciones UE & Comisión & 0 & 13 & 13 & 4 & 78 & 108 \\
\cline { 2 - 8 } & $\begin{array}{l}\text { Parlamento } \\
\text { Europeo }\end{array}$ & 0 & 9 & 9 & 2 & 36 & 56 \\
\hline
\end{tabular}




\section{TABLA 1 (cont.)}

Puntuaciones de intermediación en la red OGM

\begin{tabular}{|c|c|c|c|c|c|c|c|}
\hline Tipo de organización & Organizaciones & Coordinación & Guardián & Representante & Consultor & Enlace & Total \\
\hline \multirow[t]{2}{*}{ Asesores científicos } & $\begin{array}{l}\text { Asesor } \\
\text { independiente A }\end{array}$ & 0 & 0 & 0 & 0 & 2 & 2 \\
\hline & $\begin{array}{l}\text { Asesor } \\
\text { independiente B }\end{array}$ & 0 & 0 & 0 & 0 & 0 & 0 \\
\hline \multirow{3}{*}{$\begin{array}{l}\text { Organizaciones } \\
\text { agrarias }\end{array}$} & COPA-COGECA & 0 & 10 & 10 & 2 & 34 & 56 \\
\hline & IFOAM & 0 & 3 & 3 & 0 & 6 & 12 \\
\hline & Demeter & 0 & 1 & 1 & 0 & 2 & 4 \\
\hline \multirow{4}{*}{$\begin{array}{l}\text { Organizaciones } \\
\text { industriales }\end{array}$} & COCERAL & 0 & 0 & 0 & 0 & 0 & 0 \\
\hline & Euro-commerce & 2 & 10 & 10 & 0 & 0 & 22 \\
\hline & Europabio & 2 & 14 & 14 & 0 & 12 & 42 \\
\hline & FEDIOL & 0 & 1 & 1 & 0 & 0 & 2 \\
\hline \multirow{2}{*}{$\begin{array}{l}\text { Organizaciones de } \\
\text { consumidores }\end{array}$} & Euro Coop & 0 & 1 & 1 & 2 & 52 & 56 \\
\hline & BEUC & 0 & 1 & 1 & 0 & 54 & 56 \\
\hline \multirow{3}{*}{$\begin{array}{l}\text { Organizaciones } \\
\text { medioambientales }\end{array}$} & EEB & 0 & 1 & 1 & 0 & 10 & 12 \\
\hline & $\begin{array}{l}\text { Friends of the } \\
\text { Earth }\end{array}$ & 0 & 2 & 2 & 0 & 22 & 26 \\
\hline & Greenpeace & 0 & 5 & 5 & 0 & 40 & 50 \\
\hline ONGS & $X$-minus-Y & 0 & 0 & 0 & 0 & 0 & 0 \\
\hline
\end{tabular}

Fuente: Elaboración propia.

El estatus de la Comisión como el principal intermediario en la red debe situarse en perspectiva a la hora de examinar la naturaleza de los papeles de intermediación que desempeña. La suma de las puntuaciones como "coordinador" y "guardián" son inferiores a las de "representante" y "consultor" juntas3. A pesar de la ligera distancia numérica, se trata de una diferencia significativa porque las mediciones se llevan a cabo en términos de puntuaciones absolutas, es decir, por el número de veces que otros actores han posicionado a la Comisión en ese papel de intermediación. Por lo tanto, estos resultados parecen confirmar la primera hipótesis: que la Comisión está realizando papeles de intermediación que son más débiles en términos de influencia política. No obstante, teniendo en cuenta todas las puntuaciones a la vez, la Comisión tiene las tasas más altas, lo que apunta a la centralidad de la Comisión en el conjunto de la red. La Tabla 2 corrobora esta última observación, lo que indica que la Comisión retiene su

3 Las puntuaciones como "enlace" no se incluyen en esta medición porque pueden distorsionar las posiciones en cuanto las formas de intermediación fuertes y débiles dado que hay un gran número de subgrupos y por lo tanto "enlace" obtendría sistemáticamente altas puntuaciones distorsionando la posición relativa de la Comisión. 
posición central, aunque seguida de cerca por otros actores, en particular por el Parlamento Europeo. El análisis del tamaño de la "egored" y de la centralidad "betweenness" son medidas adicionales interesantes que arrojan más luz sobre la centralidad de la Comisión, independientemente de sus diferentes puntuaciones de intermediación.

\section{TABLA 2}

Centralidad de los actores en la red OGM

\begin{tabular}{|c|c|c|c|}
\hline $\begin{array}{c}\text { Tipo de } \\
\text { organización }\end{array}$ & Organizaciones & $\begin{array}{l}\text { Tamaño de la } \\
\text { "egored"* }\end{array}$ & $\begin{array}{c}\text { Centralidad } \\
\text { "betweenness"** }\end{array}$ \\
\hline \multirow[t]{2}{*}{ Instituciones UE } & Comisión & 17 & 16,743 \\
\hline & Parlamento Europeo & 15 & 3,238 \\
\hline \multirow[t]{2}{*}{ Asesores científicos } & Asesor independiente $A$ & 9 & 0,061 \\
\hline & Asesor independiente B & 1 & 0,000 \\
\hline \multirow{3}{*}{$\begin{array}{l}\text { Organizaciones } \\
\text { agrarias }\end{array}$} & COPA-COGECA & 15 & 3,238 \\
\hline & IFOAM & 11 & 0,686 \\
\hline & Demeter & 10 & 0,143 \\
\hline \multirow{4}{*}{$\begin{array}{l}\text { Organizaciones } \\
\text { industriales }\end{array}$} & COCERAL & 6 & 0,000 \\
\hline & Euro-commerce & 12 & 1,216 \\
\hline & Europabio & 13 & 2,457 \\
\hline & FEDIOL & 8 & 0,061 \\
\hline \multirow{2}{*}{$\begin{array}{l}\text { Organizaciones de } \\
\text { consumidores }\end{array}$} & Euro Coop & 15 & 3,544 \\
\hline & BEUC & 15 & 3,348 \\
\hline \multirow{3}{*}{$\begin{array}{l}\text { Organizaciones } \\
\text { medioambientales }\end{array}$} & EEB & 12 & 0,472 \\
\hline & Friends of the Earth & 13 & 1,415 \\
\hline & Greenpeace & 14 & 3,021 \\
\hline ONGs & $X$-minus- $Y$ & 6 & 0,000 \\
\hline
\end{tabular}

* Puntuación absoluta.

** Porcentaje.

Fuente: Elaboración propia.

El tamaño de la "egored" es una medición de la cifra absoluta de los otros actores en la red que han señalado a ese actor como receptor de sus interacciones, incluyendo la propia. La importancia de la Comisión es la más elevada en la red, alcanzando puntuaciones de 17 en una matriz formada por 18 agentes. Sin embargo, este resultado no puede ser exagerado, ya que es esencial apuntar la relevancia de otros actores, particularmente el Parlamento Europeo, COPA-COGECA (agricultores), BEUC (consumidores), Euro-coop (consumidores) y Greenpeace (medio ambiente). La cen-

32 tralidad "betweenness" ofrece una medición de más sutil sobre la centralidad y pue- 
de calificar mejor los resultados anteriores al medir las puntuaciones intermedias de cada actor como un porcentaje de todas las otras interacciones dentro de la red independiente de la dirección de los vínculos. Se asume que cuanto más dependan los actores de otro actor específico para hacer las conexiones, más favorecida será la posición de este actor, independientemente de los papeles de intermediación. En este sentido, la Comisión tiene una posición primordial en contraste con otros agentes, lo que indica el papel central desempeñado por esta institución.

Los resultados de las Tablas 1 y 2 revelan características importantes de otros actores cruciales en la red OGM, por ejemplo, la centralidad del Parlamento Europeo, que ha obtenido unas puntuaciones particularmente elevadas. Esto puede explicarse por su posición en el procedimiento de codecisión, pero también por el activismo de muchos miembros del Parlamento en esta materia. Volviendo al papel de la Comisión en las interacciones a nivel de la UE, los datos anteriores indican que la Comisión tiene un perfil de intermediación relativamente débil en la red de OGM (más "representante-consultor" que "coordinador-guardián"), pero a pesar de ello, goza de una relativa centralidad y de presencia en el conjunto de la red, ya que la mayoría de los flujos de interacción pasan por esta institución. A fin de comprender esto, podríamos recordar de nuevo su grado de liderazgo político moral, la capacidad institucional y las competencias gerenciales.

En las primeras etapas del proceso de formulación de la política, la Comisión trasladó el terreno de los OGM de la DG de Agricultura a la DG Sanco (Sanidad y Protección del Consumidor), lo que representó un movimiento político muy significativo. Las entrevistas aportan pruebas de la existencia de una visión positiva entre la mayoría de los actores políticos sobre la DG Sanco. Con toda probabilidad, esto permitió a la Comisión ejercer una relativo (aunque débil) grado de liderazgo moral, que se refleja en sus papeles de intermediación débil como "coordinador" y "guardián". La DG Sanco favoreció un modelo de actitud política de "la seguridad primero" en un nada disimulado intento de recuperar la confianza de los Estados miembros más críticos (en particular Alemania, Austria, Italia, Grecia y Luxemburgo) y de los actores escépticos sobre los OGM. Sin embargo, alcanzar un acuerdo de compromiso no fue tarea fácil. La mayoría de los entrevistados señalaron que los debates políticos se llevaron a cabo en un clima de disputas constantes y con tendencia a ser muy emocionales.

La cuestión de la regulación de los OGM es muy compleja por lo menos en tres dimensiones técnicas: científica, jurídica (el complejo conjunto de normativas nacionales y de la UE relacionadas con los OGM) y de procedimiento (el procedimiento de aprobación recae en parte en el marco del procedimiento de "comitología”). Navegar a través de este laberinto fue un gran reto para todos los actores políticos, en particular para aquellos con una débil capacidad institucional y aquí, la Comisión se situó en el ojo del huracán. Gozaba de un fuerte conocimiento interno sobre los tecnicismos jurídicos y de procedimiento y, simultáneamente, disponía de un fuerte conjunto de recursos externos para explotar el conocimiento científico. El Parlamento Europeo era mucho más débil en estas tres dimensiones y los Estados miembros sa- 
bían relativamente poco acerca de los marcos normativos de los demás. Por lo tanto, es muy probable que la Comisión maximizara esta situación políticamente y esto podría explicar por qué la Comisión se mantuvo en el centro de la intermediación política, a pesar de su debilitado papel como "coordinador” y "guardián”.

La red de políticas públicas OGM era una red muy amplia. Dado que esta cuestión trasciende varios ámbitos de políticas (la política agrícola, la de protección de los consumidores, la industrial, la del medio ambiente, etc.), movilizó un abanico de actores con intereses inusualmente amplio. El tamaño y la densidad de una red de políticas públicas no son cuestiones triviales, ya que establecen las condiciones para la intermediación, lo que significa que cuanto más grande y densa sea de la red, más difícil será ejercer las funciones de intermediación fuerte, en particular la de "coordinador". La competencia gerencial de la Comisión y, en concreto, la forma en que esta organización procesa las múltiples fuentes de información y las canaliza de manera selectiva, se sometió a prueba dada la multiplicidad de fuentes y de receptores de información. Los funcionarios de la Comisión entrevistados para este estudio indicaron que recibieron información en abundancia que procesaron y canalizaron de manera selectiva, transmitiéndola probablemente aplicando una solución "a gusto del consumidor". Del mismo modo, la alta densidad de las interacciones en el conjunto de la red limitaron la capacidad de la Comisión para desempeñar papeles de intermediación más fuertes, en particular como "guardián”.

\section{LA COMISIÓN EN LA ESTRATEGIA PARA EL EMPLEO}

El papel de la Comisión es muy diferente en el segundo caso de estudio. La Estrategia Europea de Empleo (EEE) es una política relativamente nueva en el contexto de la UE. Desarrollada progresivamente desde 1997 en medio de una preocupación generalizada por los altos niveles de desempleo en toda Europa, la EEE no implica transferencia alguna de competencias normativas desde el nivel nacional al nivel de la UE. En su lugar, se basa en la coordinación voluntaria y abierta de las políticas de los Estados miembros para con diferentes aspectos del mercado laboral en busca del incremento y la mejora del empleo (Goetschy, 2003). La decisión y ejecución de la estrategia siguen el "método abierto de coordinación" (MAC), un procedimiento en el que la Comisión está lejos de disfrutar de las prerrogativas del Tratado de las que dispone en los procedimientos legislativos convencionales del "método comunitario" (Borrás y Jacobsson, 2004; Zeitlin, 2005). En muchos sentidos, el MAC es la prueba de fuego de la capacidad de la Comisión para ejercer papeles de intermediación fuerte. En contraste con las controversias relacionadas con los OGM, en las que la Comisión fue siempre parte de la solución, en el MAC la Comisión corre el riesgo de ser parcialmente marginada, especialmente por el hecho de que la EEE es un proceso muy dominado por los Estados miembros, que están representados en el Comité de Empleo ${ }^{4}$, un comité es-

4 El Comité de Empleo es el comité más importante en esta área política formado por representantes de los Estados miembros. Se ha incluido como actor único porque el análisis de los papeles de intermediación contempla la posición institucional frente a otras instituciones. La accesibilidad a los 
pecialmente diseñado y muy poderoso. El bajo perfil del Parlamento Europeo y el inexistente papel del Tribunal Europeo de Justicia implican que hay muy pocas interacciones interinstitucionales en las que la Comisión pueda actuar como intermediario.

La evidencia empírica resulta muy interesante en este sentido, ya que parece desmentir en parte la hipótesis de una Comisión marginada. Las mediciones de intermediación de la Tabla 3 ofrecen datos sobre los diferentes papeles de intermediario de las organizaciones que participaron directamente en el establecimiento de las directrices sobre la EEE en 2003.

TABLA 3

Puntuaciones de intermediación en la red de políticas públicas EEE

\begin{tabular}{|l|l|c|c|c|c|c|c|}
\hline \multicolumn{1}{|c|}{$\begin{array}{c}\text { Tipo de } \\
\text { organización }\end{array}$} & Organizaciones & Coordinador & Guardián & Representante & Consultor & Enlace & Total \\
\hline $\begin{array}{l}\text { Instituciones } \\
\text { de la UE }\end{array}$ & Comisión & 2 & 9 & 9 & 6 & 24 & 50 \\
\cline { 2 - 8 } & $\begin{array}{l}\text { Comité de } \\
\text { Empleo }\end{array}$ & 0 & 0 & 0 & 0 & 2 & 2 \\
\cline { 2 - 8 } & PE & 0 & 0 & 0 & 0 & 0 & 0 \\
\hline \multirow{2}{*}{$\begin{array}{l}\text { Interlocutores } \\
\text { sociales }\end{array}$} & ETUC & 0 & 2 & 2 & 0 & 2 & 6 \\
\cline { 2 - 8 } & DA & 0 & 0 & 0 & 0 & 0 & 0 \\
\cline { 2 - 8 } & CEEP & 0 & 2 & 2 & 2 & 0 & 6 \\
\cline { 2 - 8 } & UNICE & 4 & 4 & 4 & 0 & 2 & 14 \\
\hline \multirow{2}{*}{$\begin{array}{l}\text { Otros } \\
\text { interesados }\end{array}$} & EAPN & 0 & 0 & 0 & 0 & 0 & 0 \\
\hline \multirow{2}{*}{$\begin{array}{l}\text { Instituciones } \\
\text { menores UE }\end{array}$} & COR & 0 & 0 & 0 & 0 & 0 & 0 \\
\cline { 2 - 8 } & CESE & 0 & 0 & 0 & 0 & 2 & 2 \\
\hline
\end{tabular}

Fuente: Elaboración propia.

La suma de las puntuaciones de los papeles de la Comisiones como "representante" y "consultor" son más elevadas que las que obtiene como «coordinador» y "guardián” juntas. Al igual que en el caso OGM, estos resultados sugieren que, en términos relativos, la Comisión ha desempeñado principalmente papeles de intermediación débiles en la red de políticas en torno a directrices de la EEE. Sin embargo, es importante subrayar que, en contraste con el anterior caso OMG, la Comisión ejerció un inesperado pero claro papel de coordinador dentro del grupo de instituciones de

miembros del Comité hizo bastante fiable la recopilación de datos. Desgraciadamente no fue así en el caso de los organismos transgénicos donde los representantes nacionales en el comité correspondiente no estuvieron disponibles para entrevistas o para recabar datos cuantitativos en relación con sus interacciones institucionales. 
la UE. Volveremos a ello más adelante. Por otra parte, el total de las puntuaciones de la Tabla 3 y las distintas mediciones de la Tabla 4 revelan sistemáticamente a la Comisión en el núcleo del conjunto de la red EEE.

\section{TABLA 4}

Distintas mediciones sobre la centralidad de los actores en la red EEE

\begin{tabular}{|c|c|c|c|}
\hline Tipo de organización & Organizaciones & $\begin{array}{l}\text { Tamaño de la } \\
\text { "egored" }\end{array}$ & $\begin{array}{l}\text { Centralidad } \\
\text { "betweeness" }\end{array}$ \\
\hline \multirow[t]{3}{*}{ Instituciones de la UE } & Comisión & 8 & 41,667 \\
\hline & Comité de Empleo & 3 & 0,926 \\
\hline & PE & 4 & 0,000 \\
\hline \multirow[t]{4}{*}{ Interlocutores sociales ${ }^{6}$} & ETUC & 5 & 5,556 \\
\hline & DA & 1 & 0,000 \\
\hline & CEEP & 5 & 4,630 \\
\hline & UNICE & 6 & 25,926 \\
\hline Otros interesados 7 & EAPN & 2 & 0,000 \\
\hline \multirow{2}{*}{$\begin{array}{l}\text { Instituciones menores }{ }^{8} \text { de } \\
\text { la UE }\end{array}$} & CESE & 3 & 1,852 \\
\hline & CoR & 1 & 0,000 \\
\hline
\end{tabular}

Fuente: Elaboración propia.

Una medición del tamaño de las "egoredes" de los 10 actores muestra que la puntuación de la Comisión es la más alta (8), seguida por la UNICE, ETUC y CEEP. Esto no es sorprendente, ya que estas organizaciones se corresponden con los interlocutores sociales que gozan de una posición privilegiada en el ámbito de la política del mercado de trabajo. La centralidad relativa de estos actores y, en particular de la Comisión Europea DG Empleo, se refleja una vez más en la medición de centralidad “betweenness", que mide la distancia de un actor respecto a los demás actores, teniendo en cuenta la posición del actor en estudio. Aquí, las diferencias de centralidad están exacerbadas ya que la Comisión y la UNICE son los únicos actores con posiciones significativas.

Uno de los más sorprendentes hallazgos de las mediciones cuantitativas de las Tablas 3 y 4 es el perfil relativamente bajo del Comité de Empleo en el conjunto de la red de políticas. En contraste con el complejo equilibrio de poderes interinstitucional en los procedimientos reglamentarios (en particular en el procedimiento de codeci-

5 ETUC: European Confederation of Trade Unions; DA: Danish Employers' association, CEEP: European association of public employers; UNICE: European Business Association.

7 ECOSOC: Economic and Social Committee; CoR: Committee of the Regions. 
sión), las decisiones finales relativas a las directrices de la EEE se tomaron en el Comité de Empleo antes de ser elevadas al Consejo de Ministros. Sobre esa base, uno podría haber esperado que las puntuaciones del Comité de Empleo fueran mucho mas elevadas en ambas tablas, sobre todo en las mediciones del tamaño de la "egored" y de la centralidad "betweenness" en la Tabla 4, ya que el Comité de Empleo podría ser el receptor natural de la mayoría de las interacciones. Las entrevistas cualitativas, sin embargo, nos dicen que los miembros del Comité de Empleo prefieren desarrollar sólidos lazos con otros representantes nacionales, junto con sus propios interlocutores sociales nacionales y de la Comisión, pero no con los interesados supranacionales. Y también a la inversa: los interesados supranacionales entrevistados no informaron de ningún contacto directo significativo con el Comité de Empleo, pero sí de muchos con la Comisión. Esto explica el aislamiento relativo del Comité de Empleo en las mediciones cuantitativas de la red, así como el papel de coordinación de la Comisión en el seno del grupo formado por las instituciones de la UE. En ausencia de lazos directos entre el Comité de Empleo y los interesados supranacionales, la Comisión ha desarrollado un papel de guardián y representante, siendo prácticamente el único actor que transmitía las opiniones de interesados supranacionales al Comité de Empleo y viceversa. Y lo hizo manteniendo muchas reuniones bilaterales.

Con el fin de explicar por qué la Comisión tiene este perfil específico de intermediación en la toma de decisiones sobre la EEE, se podría volver a las tres características organizativas internas antes mencionadas, a saber, el grado de liderazgo moral, su capacidad institucional y la manera en que ejerció su competencias gerencial.

La Comisión ha sido tradicionalmente fuerte en el diálogo social y en las iniciativas normativas en el ámbito de la política de empleo, que son dos herramientas adyacentes a la EEE. Esto ha permitido a la Comisión a ejercer un liderazgo moral relativamente fuerte en los procedimientos del método abierto de coordinación, vinculándolos estratégicamente a estos otros instrumentos (Goetschy, 2003). Sin embargo, la relativa fortaleza moral de la Comisión se ha visto socavada en parte por las disputas internas entre la DG de Empleo y la DG de Economía y Finanzas en relación con sus diferentes puntos de vista sobre el mercado de trabajo, como informaron varios de los entrevistados. En la toma de decisiones en 2003 de las directrices de la EEE, los actores con intereses optaron masivamente por la DG de Empleo como intermediario válido con el Comité de Empleo, mientras que la DG de Economía y Finanzas nunca asumió esa posición, buscando en su lugar ejercer alguna influencia normativa sobre el Consejo. LA DG de Empleo administró en parte su posición central en el diálogo social para extrapolarla a los procedimientos del MAC, ya que era contemplada como un intermediario válido por las organizaciones en la red de políticas.

La política de empleo es un campo en el que el conocimiento intensivo es menor que el ámbito de los OGM. En términos comparativos, esto podría haber supuesto menos demanda de capacidad institucional de los actores involucrados, en particular de la Comisión. Sin embargo, no debe subestimarse la complejidad de las cuestiones de la política de empleo, dadas las importantes diferencias en los mercados de traba- 
jo en los 25 Estados miembros y la fuerte dimensión legal o cuasi legal de los contenidos de la política laboral. Los extensivos, más que intensivos, recursos de conocimientos requeridos por este campo no situaron la Comisión en una mejor posición frente a las otras organizaciones. Las organizaciones de interlocutores sociales están tradicionalmente bien dotadas de recursos de conocimientos. Esto lleva a la siguiente cuestión relativa a la competencia gerencial de la Comisión. La red de políticas públicas en torno a la EEE es comparativamente más pequeña que la red OGM. Esto podría haber reducido significativamente la necesidad de intermediación en términos generales. Sin embargo, el aislamiento del Comité de Empleo dio a la Comisión la oportunidad de actuar como "guardián". La competencia gerencial de la Comisión se puso de manifiesto con el uso estratégico de la información proporcionada por los interesados y transmitida al Comité de Empleo, así como por su enfático apoyo para incluir en la red a otros interesados además de los interlocutores sociales.

\section{CONCLUSIÓN: EL INTERMEDIARIO RESISTENTE EN LAS REDES}

Estos resultados apuntan abrumadoramente en la dirección de que la Comisión es un intermediario resistente en las redes de políticas públicas. La primera hipótesis formulada al comienzo de este artículo -que la Comisión iba a ser cuestionada por otras instituciones a nivel de la UE y por otros interesados- sólo se confirma parcialmente, ya que es cierto que los interlocutores sociales y los grupos de consumidores tienen gran importancia en las redes examinadas, pero no hasta el punto de asumir el papel de la Comisión como el intermediario más central. El precio que la Comisión tuvo que pagar, sin embargo, fue el de tener menos influencia con papeles de intermediación débiles, lo que confirma la segunda hipótesis acerca de una Comisión con un perfil de intermediación más débil.

Lejos de empantanarse por la presión contextual a la que ha estado sometida desde el año 2000, la Comisión Europea se las ha arreglado para mantener una posición destacada dentro de las redes de políticas públicas en la UE. Los dos casos objeto de examen, que son casos extremos debido a las presiones particularmente fuertes ejercidas sobre esta institución, han demostrado que la Comisión desempeña múltiples papeles de intermediación simultáneamente y que ha logrado mantener una clara centralidad en todos estos papeles cuando interviene en el flujo de interacciones políticas dentro de las redes. Sin embargo, algunas de estos papeles son más relevantes que otros en términos de influencia política, dependiendo de la dirección y del destino final de las interacciones. Si se hace un balance entre las puntuaciones de los roles de intermediación fuerte frente a los de intermediación débil, se llega a la conclusión de que la Comisión desempeña un papel relativamente débil. Es especialmente llamativo que la Comisión fue la única capaz de trabajar como coordinador en el seno del grupo de instituciones de la UE en la red EEE, lo que refleja que, después de todo, la modificación de las condiciones interinstitucionales ha afectado a la posición relativa de la Comisión en este subconjunto de interacciones. Los datos revelan 38 igualmente que la Comisión es un "guardián" dominante en ambas redes. Parece 
como si la mayoría (si no todos) de los interesados en el ámbito de la política volvieran sus ojos y su atención hacia la Comisión como punto de acceso crucial para influir en las decisiones. Sin embargo, los papeles fuertes de coordinador y guardián se anularon por los papeles débiles como "representante" y "consultor". En su papel de representante, la Comisión tiene una posición fundamental transmitiendo la información de las otras grandes instituciones de la UE a los interesadas a nivel de la UE. Lo qué es más interesante, sin embargo, es que los datos indican que los interesados y las otras organizaciones parecen estar utilizando a la Comisión como un intermediario en sus interacciones mutuas (dentro y entre grupos similares de interesados), ya que la Comisión sistemáticamente obtiene las puntuaciones más altas en papeles como "consultor" y "enlace" en ambas redes.

Volviendo a las consideraciones teóricas anteriores sobre el papel de la Comisión, este estudio ofrece una imagen matizada de los distintos papeles de intermediación desempeñados por la Comisión de 2000 a 2005. Coincidiendo con la consideración intergubernamental, este artículo pone de manifiesto que la Comisión es un actor limitado en los complejos procesos políticos en Bruselas, en particular en casos como los anlizados, concretamente, los casos en que la propia Comisión ha estado bajo presión. Pero los hallazgos actuales también retratan a la Comisión como una organización que es capaz de movilizar sus recursos internos y externos con el fin de posicionarse centralmente en las densas e informales interacciones que tienen lugar dentro de las complejas redes de políticas con base en Bruselas. En otras palabras, una organización que aún está en el núcleo del proceso de formulación de políticas en la UE y que es capaz de adaptarse y acomodarse a los siempre cambiantes contextos institucional y ambiental. Las conclusiones de este artículo, naturalmente, sólo son válidas para el período de tiempo en estudio, a saber, en los cinco primeros años de la década 2000. Los importantes cambios del segundo semestre de 2005, particularmente en relación con la aparente reafirmación política de la Comisión Barroso pueden estar reformulando otra vez el ímpetu de esta institución frente a otras instituciones de la UE y los actores interesados en la elaboración de políticas en algunas áreas concretas. Esto plantea una serie de nuevas preguntas sobre el papel de la Comisión después del año 2005, que deben ser abordados en un futuro próximo.

\section{REFERENCIAS BIBLIOGRÁFICAS}

Ansell, C., Parsons C. y Darden K. (1997), “Dual networks in European Regional Development Policy", Journal of Common Market Studies, 35 (3): 347-75.

Borrás, S. y Jacobsson K. (2004), “The Open Method of Coordination and the New Governance Patterns in the EU”, Journal of European Public Policy, 11 (2): 185208.

Borrás, S. y Olsen, H.P. (2006), “Combining Qualitative Methods with Quantitative Social Network Analysis: Promise, Problems, Pay-offs and Potentials” En P. 
Bogason, y M. Zølner, eds., Analysing Democratic Network Governance: Methodological Issues. Londres: Palgrave-Macmillan.

Burns, C. (2004), "Codecision and the European Commission: A study of declining influence?”, Journal of European Public Policy, 11 (1): 1-18.

Börzel, T. (1998), “Organizing Babylon - On the Different Conceptions of Policy Networks" Public Administration, 76 (2): 253-73.

Calonge Velásquez, A. (2004), “Gobernanza Europea: El papel de las instituciones y la centralidad de la Comisión" Circunstancia 3, http://www.ortegaygasset.edu/contenidos.asp?id_d=378 (Consulta: Noviembre 2008).

Christiansen, T. (2001), "The European Commission: Administration in Turbulent Times”, en J. Richardson, ed., European Union. Power and Policy-Making. Londres: Routledge.

Cram, L. (1997), Policy-Making in the EU. Londres: Routledge.

Dimitrakopoulos, D.G. (2004), “Introduction” in D.G. Dimitrakopoulos ed., The Changing European Commission. Manchester: Manchester University Press.

Garret, G. (1992), “International cooperation and institutional choice: The EC's Internal Market”, International Organization, 46: 533-60.

Goetschy, J. (2003), “The European Employment Strategy, Multi-level governance and Policy Coordination: Past, Present and Future”, en J. Zeitlin y D.M. Trubek, eds., Governing Work and Welfare in a New Economy. Oxford: Oxford University Press.

Gould, R. y Fernandez R. (1989), "Structures of Mediation: A Formal Approach to Brokerage in Transaction Networks”, Sociological Methodology, 19: 89-126.

Judge, D. y Earnshaw D. (2002), "The European Parliament and the Commission Crisis: A New Assertiveness?”, Governance, 15 (3): 345-74.

Kassim, H. y Menon A. (2004), “European integration since the 1990s: Member States and the European Commission”, ARENA working paper 6/04.

Laffan, B. (1997), "From policy entrepreneur to policy manager: the challenge facing the European Commission” Journal of European Public Policy, 4 (3): 422-438.

Marks, G., Hooghe L. y Blank K. (1997), “European Integration from the 1980s: StateCentric vs. Multi-level Governance", Journal of Common Market Studies, 32 (3): $40 \quad 341-78$. 
Matlary, J. (2000), "The Role of the Commission: A Theoretical Discussion" en N. Nugent, ed., At the Heart of the Union. Londres: Macmillan.

Majone, G. (2002), "The European Commission: The Limits of Centralization and the Perils of Parliamentarization”, Governance, 15 (3): 375-92.

Metcalfe, L (1996), “The European Commission as a Network Organization”, Publius, $26(4): 43-62$.

Metcalfe, L. (2000), "Reforming the Commission: Will Organizational Efficiency Produce Effective Governance?", Journal of Common Market Studies, 38 (5): 817-41.

Moravcsik, A. (1999), “A New Statecraft? Supranational Entrepreneurs and International Cooperation”, International Organization, 53 (2): 267-306.

Nugent, N. (2000), "Themes and Prospects", in N. Nugent, ed., At the Heart of the Union. Londres: Macmillan.

Peterson, J. (1991), “Technology Policy in Europe: Explaining the Framework Programme and Eureka in Theory and Practice”, Journal of Common Market Studies, 29 (1): 269-90.

Peterson, J. (2004), “Policy networks”, en A. Wiener and T. Diez, eds., European Integration Theory. Oxford: Oxford University Press.

Pierson, P. (1998), "The Path to European Integration: A Historical-institutionalist Analysis", en W. Sandholdtz, y A. Stone Sweet, eds., European Integration and Supranational Governance. Oxford: Oxford University Press.

Pollack, M.A. (1997), "Delegation, Agency and Agenda Setting in the European Community”, International Organization, 51 (1): 99-134.

Pollack, M. A. y G.C. Shaffer (2005), "Biotechnology Policy. Between National Fears and Global Disciplines", en H. Wallace, W. Wallace y M. A. Pollack, eds., PolicyMaking in the European Union. Oxford: Oxford University Press.

Pollitt, C. y Bouckaert G. (2004), Public Management Reform. A Comparative Analysis. Oxford: Oxford University Press.

Rhodes, R.A.W (1990), "Policy Networks: A British Perspective”, Journal of Theoretical Politics, 2 (2): 293-317.

Schmidt, S.K. (2004), “The European Commission's Powers in Shaping European Policies”, en D. Dimitrakopoulos, ed., The Changing European Commission. Manchester: Manchester University Press. 
Skogstad, G. (2003), “Legitimacy and/or policy effectiveness? Network governance and GMO regulation in the European Union", Journal of European Public Policy, $10(3): 321-38$.

Talleberg, J. (2002), "Paths to Compliance: Enforcement, Management, and the European Union”, International Organization, 56: 609-643.

Wincott, D. (2001), "Looking Forward or Harking Back? The Commission and the Reform of Governance in the European Union", Journal of Common Market Studies, 39 (5): 897-911.

Zeitlin, J. and P. Pochet (eds.) (2005), The open method of co-ordination in action: The European employment and social inclusion strategies. Nueva York: P.I.E.-Peter Lang. 